\title{
FONTES DE INFORMAÇÃO ESPECIALIZADA EM AFRICANIDADES
}

\begin{abstract}
Resumo: Este trabalho objetiva identificar algumas fontes de informação, de diferentes tipologias, que versam sobre africanidades. $\mathrm{Na}$ metodologia, foram aplicados os seguintes métodos na etapa de coleta de dados: levantamento de fontes de informação relacionadas à África na literatura nacional e internacional da Ciência da Informação; pesquisa em motores de busca para a identificação de sites e/ou instituições produtoras ou responsáveis por fontes relacionadas à África; obtenção de informações sobre fontes relacionadas à África mediante contato com pesquisadores da área de Ciência da Informação e/ou através de contatos de pesquisadores africanos. $\mathrm{Na}$ etapa de análise dos dados foram: verificadas informações referentes a outras fontes sobre africanidades; examinadas a disponibilidade de acesso às fontes através da Internet; e organizadas as informações sobre as fontes mediante o preenchimento dos critérios descritos no tópico "Apresentação e Descrição das Fontes de Informação". Como resultado dessas etapas, foi elaborado um guia com 19 fontes de informação especializada em africanidades. O tema é considerado razoável e relevante para os usuários interessados nessa temática e para os profissionais da informação que atuam, seja no campo da formação e disseminação de acervos, seja na pesquisa e geração de conhecimentos sobre fontes de informação que tratam a respeito da África.
\end{abstract}

Palavras-chave: Fontes de Informação Especializada - África. Guia de Fontes de Informação - Africanidades. Ciência da Informação.

\author{
Wellington Marçal de Carvalho \\ Universidade Federal de Rondônia \\ Doutor em Literaturas de Língua Portuguesa \\ (PUC Minas). Docente no Departamento de \\ Ciência da Informação / Biblioteconomia da \\ Universidade Federal de Rondônia. \\ marcalwellington@yahoo.com.br \\ Angerlânia Rezende \\ Docente no Departamento de Ciência da \\ Informação / Biblioteconomia da \\ Universidade Federal de Rondônia \\ Mestre em Ciência da Informação (UFPE). \\ Docente no Departamento de Ciência da \\ Informação / Biblioteconomia da \\ Universidade Federal de Rondônia \\ lanny.rezende3@gmail.com
}

Gracielle Mendonça Rodrigues Gomes Bibliotecária da Biblioteca Universitária / Sistema de Bibliotecas da UFMG. Doutora em Gestão e Organização do Conhecimento (ECI/UFMG). Bibliotecária da Biblioteca Universitária / Sistema de Bibliotecas da UFMG.

graciellemendonca@yahoo.com.br

\section{SPECIALIZED INFORMATION SOURCES IN AFRICANITIES}

\begin{abstract}
This study aims to identify some sources of information of different types, about Africanities. In the methodology, the following methods were applied in the data collection stage: survey of information sources related to Africa in the national and international Information Science literature; search engine search for the identification of websites and/or institutions producing or responsible for sources related to Africa; and obtaining information from Africa-related sources through contact with Information Science researchers and/or through contacts with African researchers. In the data analysis stage, were: verified information referring to other sources on Africanities; examined the availability of access to sources through the Internet; organized information about sources by fulfilling the criteria described in the topic "Presentation and Description of Information Sources". As a result of these steps, a guide was drawn up with 19 sources of information specializing in Africanities. The theme is considered reasonable and relevant for users interested in this theme and for the information professionals who work, whether in the field of collections formation and dissemination, or in research and knowledge generation about information sources that deal with Africa.
\end{abstract}

Keyword: Specialized Information Sources - Africa. Guide to Information Sources - Africanities. information Science. 


\section{INTRODUÇÃO}

Já de partida é prudente sublinhar a dificuldade assinalada por teóricos do campo biblioteconômico quanto à possível convergência ainda por se fazer quando a tarefa é conceituar, ou, definir, em termos precisos, o que se entende por "fonte de informação", ou, "rede de informação". O especificador “especializada", pós-posto ao termo, não ameniza a tarefa.

Nesse sentido, ao prescrutar parte das explanações dos teóricos brasileiros, dos quais poderiam ser citados, pelo menos, os professores Paulo da Terra Caldeira (2008) e Murilo Bastos da Cunha (2010) e, de igual maneira, as professoras Bernadete Santos Campello (2008) e Beatriz Valadares Cendón (2003), poder-se-ia cotejar a seguinte delimitação conceitual: as fontes de informação especializada são artefatos construídos por seres humanos que agenciam uma série de elementos informacionais sobre determinado recorte / especialidade da existência cotidiana. Esses artefatos se prestam, pelo menos para isso é que foram concebidos, a sanar uma demanda informacional específica e, não obrigatoriamente, podem apontar novos caminhos em virtude do que resultar o ato de compulsar esses mecanismos.

Como se verá, em seguida, essas fontes de informação especializada são de uma infinidade de tipos, o que acentua a dinamicidade inerente ao universo de sua produção. De modo bastante geral, de acordo com Campello e Caldeira (2008) e Cunha (2010) elas se distribuem em bases de dados bibliográficas de texto completo ou referenciais, bem como, em bases fatuais (de forte caráter numérico). Isso é uma síntese de risco assumido.

O bom usufruto desse mundo de possibilidades de organização "interessada" (para usar uma metáfora de Umberto Eco (1993)) de informações exige dedicação do profissional bibliotecário em mergulhar numa pletora de agregadores de conteúdo, fornecedores, sobretudo porque esse é um espaço em que se cruzam interesses de toda ordem, inclusive de cunho mercadológico.

Essa aproximação pode tomar como ancoragem manuais bastante didáticos que são a estrutura do percurso pedagógico de disciplinas dos cursos superiores de Biblioteconomia, no elenco das disciplinas que tratam das "fontes de informação". Da obra elaborada pelo professor da Universidade de Brasília (UnB), Murilo Bastos da Cunha (2010), à título de ilustração, podem ser focadas algumas espécies dessas fontes. 
Antes, porém, cumpre dizer que Cunha (2010), para cada um dos capítulos, aborda, entre outros aspectos, a definição, a tipologia, a função, um roteiro sugerido de como proceder à avaliação daquele tipo específico de fonte e o mais interessante, uma respeitável enumeração das principais fontes, tanto no âmbito internacional, quanto brasileiras, com uma sintética, porém, precisa apresentação particularizada. Dedica-se um capítulo para as enciclopédias, para os dicionários, para as fontes biográficas, as fontes geográficas, etc. Dentro de cada tipo de fonte procede-se a uma verticalização que bem espelha a multiplicidade em que se desdobra cada fonte. No rol dos itens a serem observados em momento de avaliação, podem ser citados: cobertura; arranjo; autoridade da fonte; formas de acesso; plano de atualização; etc.

De natureza similar é a obra clássica organizada por Campello e Caldeira (2008) que discute, por exemplo, a função da TV, dos jornais, das bibliotecas, dos arquivos, dos museus, da internet, etc., como expressivas fontes de informação. No que diz respeito aos arquivos, cuja articulação enquanto fonte de informação especializada parece indubitável, vale destacar a constatação dos pesquisadores José Maria Jardim e Maria Odília Fonseca (2008), para quem devem ser envidados esforços, pelos profissionais da informação, para a produção de obras de referência a partir do que contém essas instituições arquivísticas.

No capítulo sobre a internet, o professor Angelo de Moura Guimarães (2008), ao narrar o percurso desse importante agenciamento disruptivo elaborado por humanos, volta os olhares para alguns motores de busca, meta-buscadores e destaca o caráter das listas de discussão que, ao reunirem comunidades de prática com interesses específicos, fazem desses colégios "invisíveis" perfeitamente enquadrados na noção de fonte de informação especializada. Um exemplo, que extrapola aqueles levantados pelo pesquisador, seria a lista de discussão mantida pela Comissão Brasileira de Bibliotecas Universitárias, vinculada à Federação das Associações de Bibliotecários (FEBAB).

Uma faceta que merece também ser problematizada diz respeito às fontes de informação que se desdobram do esforço orquestrado coletivamente. Esse parece ser o caso, por exemplo, das redes, ou consórcios de âmbito nacional, captaneadas pelo Instituto Brasileiro de Informação em Ciência e Tecnologia (IBICT), atualmente, e argutamente percebidas por Cendón (2005, p. 83). São elas: a Rede Bibliodata (cuja importância para a catalogação cooperativa, no Brasil, foi solidamente pavimentada e, por hora, encontra-se em fase de diagnóstico); o Programa de Comutação Bibliográfica (COMUT) (que mantém base 
de dados, de instituições associadas, de coleções de periódicos de interesse da comunidade pesquisadora) e, por fim, mas não menos importante, o Catálogo Coletivo Nacional, mais conhecido por sua sigla, o CCN (também em fase de diagnóstico pelo corpo administrativo central responsável).

Na mesma linha pode ser considerada a Rede Cariniana, também sob a chancela do IBICT, que se preocupa, entre outros aspectos, com os protocolos de preservação digital dos Repositórios Institucionais associados. Repositórios institucionais são bibliotecas digitais que, outra coisa não são, do que, por tabela, robustas fontes de informação especializadas em seus domínios específicos.

Tempos de marcado "contingenciamento", em termos orçamentários, como os que atravessa o Brasil nesses últimos temerosos anos, apenas reforçam a pertinência de se manter a aquisição consorciada, já existente por quase 20 anos, do Portal de Periódicos, tutelado pela Coordenação de Aperfeiçoamento de Pessoal de Nível Superior (CAPES). Nesse local disponibilizam-se várias fontes de informação de feição, inclusive, especializada. Vale ressaltar que uma parte do processo de renovação, assinatura e desbastamento de conteúdo é feito com o trabalho voluntário de bibliotecários especialistas, denominados "help desks", que representam todas as regiões geográficas brasileiras, pré-definidos pela coordenação do Portal.

Ainda, nesse aspecto, registra-se a relevância da Plataforma Lattes, fonte estratégica para várias ações e políticas encaminhadas pelo Conselho Nacional de Desenvolvimento Científico e Tecnológico (CNPq). Dos vários usos que se fazem da enormidade de informações registradas pelos "donos" dos currículos, por hora, cumpre lembrar a possibilidade de extração de dados para recompilações de toda ordem. Por conta disso, um consulente, ou pesquisador, ou ainda, um tomador de decisão compulsará a Plataforma Lattes para, por exemplo, levantar interessados em desenvolver trabalhos (de pesquisa, inclusive) em determinada agenda, uma vez que reconhecem aquela como uma importante fonte de informação.

Aliás, substantivo investimento reflexivo foi publicado, em 2003, por Cendón, ao analisar, rigorosamente, mais de 70 bases de dados que perfeitamente funcionam como fontes de informação para aqueles que possuem alguma interface com o mundo dos negócios. Naquele artigo a pesquisadora e professora agrupou em 10 categorias as fontes por ela 
discutidas, tais como: bases / fontes com informações estatísticas; pesquisas de mercado; informações financeiras; informações biográficas; diretórios de empresas, etc.

Dado esse panorama, este trabalho objetiva a identificação de algumas fontes de informação, de diferentes tipologias, que versam sobre algum aspecto do que poderia ser denominado como o campo de conhecimento em africanidades. Considera-se essa perspectiva razoável e relevante para os profissionais da informação que atuam, seja no campo da formação e disseminação de acervos, seja os que realizam pesquisa e geração de conhecimento, ou, ainda, os que se atrelam à dimensão mediadora entre consulentes e fontes de informação no intuito de obter insumos que problematizam, de alguma maneira, a massa crítica oriunda daquele continente ou, mesmo, construída tendo-o como objeto de reflexão, independentemente da área do saber.

A noção de "Africanidades" adotada no presente trabalho leva em conta as pertinentes considerações de pesquisadores brasileiros, dedicados aos estudos das literaturas africanas de língua portuguesa ${ }^{1}$ e, também, da área da educação. A expressão "africanidades" reportaria "ao modo de ser, de viver, [...] às marcas da cultura africana que [...] fazem parte de seu dia-a-dia" (SILVA, 2003, p. 26 citado por SOUZA, 2010, p 149-150). O termo quer traduzir a multiplicidade cultural do continente africano e enfatizar a existência de culturas diferentes e não de uma cultura única. O conceito "tem uma dimensão cultural de produção de conhecimento e, por isso mesmo, política. [...] As africanidades tomam como base a cultura e a história dos povos africanos e seus descendentes" (ALGARVE, 2004, p. 46, 48) e, poderia ser acrescentado, os múltiplos desdobramentos dessas manifestações na produção de conhecimento em todas as áreas do saber.

É interessante sublinhar o ponto explicitado pelo historiador Joseph Ki-Zerbo, de Burkina Faso, em trecho de sua introdução geral ao primeiro volume da enciclopédia, de responsabilidade da Organização das Nações Unidas para Educação, Ciência e Cultura (UNESCO), "Coleção História geral da África". Ki-Zerbo apontava a dificuldade, para o Comitê Científico Internacional, formado especificamente para aquele empreendimento, em relação às fontes:

\footnotetext{
${ }^{1}$ Foram de importância fundamental para o entendimento desse conceito as informações fornecidas pela Professora Dra. Maria Nazareth Soares Fonseca, estudiosa das literaturas africanas de língua portuguesa, inclusive na indicação de bibliografia que permitiu esquadrinhar o entendimento da expressão "africanidades". Registramos nossos agradecimentos por compartilhar, prontamente, o seu conhecimento.
} 
No que concerne ao continente africano, é preciso reconhecer que o manuseio das fontes é particularmente difícil. Três fontes principais constituem os pilares do conhecimento histórico: os documentos históricos, a arqueologia e a tradição oral. Esses três fatores são apoiados pela lingüística e pela antropologia, que permitem matizar e aprofundar a interpretação dos dados, por vezes excessivamente brutos e estéreis sem essa abordagem mais íntima. Estaríamos errados, entretanto, em estabelecer a priori uma hierarquia peremptória e definitiva entre essas diferentes fontes. (KIZERBO, 2011, p. Xxxvi).

Ainda não foi completamente superada, nem pela historiografia, tampouco por outros campos da ciência, o melindre em considerar a tradição oral enquanto fonte de informação. Esse ponto é importante e está bem destacado por M'Bow, diretor geral da UNESCO no período de 1974-1987:

Outra fonte digna de nota é a tradição oral que, até recentemente desconhecida, aparece hoje como uma preciosa fonte para a reconstituição da história da África, permitindo seguir o percurso de seus diferentes povos no tempo e no espaço, compreender, a partir de seu interior, a visão africana do mundo, e aprender os traços originais dos valores que fundam as culturas e as instituições do continente. (M'BOW, 2011, p. xxiv).

O terreno, conforme demonstrado nessa breve digressão introdutória, merece por parte de bibliotecários e outros pensadores da Ciência da Informação, substancial energia para pesquisas e, não menos importante, estratégias para identificação, avaliação e disseminação de fontes que tematizem, de diversos modos, as africanidades. As próximas partes do presente trabalho apresentam uma tentativa nesse sentido, desde o percurso metodológico realizado até os resultados alcançados.

\section{METODOLOGIA}

De forma direta, a metodologia para coleta de dados desse trabalho foi realizada através dos seguintes passos:

a) Realização de um levantamento de fontes de informação relacionadas à África na literatura nacional e internacional da Ciência da Informação;

b) Pesquisa em motores de busca para a identificação de sites e/ou instituições produtoras ou responsáveis por fontes de informação relacionadas à África; 
c) Obtenção de informações sobre fontes relacionadas à África mediante contato direto e/ou e-mail com pesquisadores da área de Ciência da Informação e/ou através de contatos de pesquisadores africanos;

d) Análise de informações referentes a outras fontes de informação sobre africanidades;

e) Verificação da disponibilidade de acesso às fontes de informação através da Internet e realização da coleta de informações mediante o preenchimento de critérios (descritos no tópico 'Apresentação e descrição das fontes de informação);

f) Elaboração de um guia de fontes de informação sobre africanidades.

A seguir, apresenta-se uma exposição detalhada do processo de busca das informações visando ao compartilhamento da experiência, das decisões tomadas e das dificuldades encontradas.

\subsection{ESTRATÉGIA DE BUSCA E COLETA DE DADOS}

Inicialmente, foram contactados pesquisadores tanto da área de Ciência da Informação que trabalham com a disciplina de 'fontes de informação', quanto com pesquisadores de países Africanos. Através de e-mail foram perguntados se conheciam bases de dados produzidas por instituições de países africanos. Obteve-se retorno positivo, em que foram apresentadas pouco mais de seis fontes de informação especializada. Essa compilação foi essencial visto a existência da escassa literatura a respeito do tema.

$\mathrm{Na}$ segunda etapa, foram executadas buscas em motores como o Google e Google Scholar, utilizando as seguintes palavras-chave: "bases de dados africanas para pesquisadores", "bases especializadas em africanidades", "bases de dados africanas", "fontes de informação africana", "information sources and africa" e "databases and africa".

Em seguida, adotou-se a estratégia de buscar em bases de dados da Ciência da Informação através do Portal de Periódicos da CAPES como LISA (Library and Information Science Abstracts), LISTA (Library, Information Science \& Tecnology Abstracts with Full Text) e SCOPUS. Nesse caso, usaram-se as palavras-chave: "information source" AND “databases" AND "africa*” e os filtros de seleção dos resultados: revisados por pares, tipo de publicação - artigos e acesso ao texto completo. 
Após a análise e compilação das fontes de informação, observou-se que algumas delas foram identificadas repetidamente nos resultados das 03 estratégias de busca utilizadas. As fontes em que não foi possível obter o acesso online ou não foram identificados os links de acesso foram excluídas dessa seleção. Portanto, como resultado final, selecionou-se um total de 19 fontes de informação associadas à África ou de origem africana sobre diversas áreas e conteúdos, que reincidentemente apareceram nos resultados a partir das estratégias adotadas e/ou por fornecerem conteúdos de alta relevância, pois não houve a intenção de apresentar uma lista exaustiva de fontes de informação devido ao formato de comunicação científica ao qual este trabalho se propõe.

A identificação e a padronização dos dados se deram mediante a apresentação e descrição das fontes selecionadas, utilizando-se critérios fundamentados e adaptados de Cendón (2003), conforme apresentados no Quadro 01. Foram definidos os parâmetros de coleta e explorados os sites de instituições produtoras e organizadoras de fontes de informação sobre a África, com o devido preenchimento de dados sobre identificação, características e tipologia de assuntos, conforme os critérios descritos a seguir:

Quadro 01 - Critérios para identificação e descrição das fontes de informação

\begin{tabular}{l|l}
\hline \multicolumn{1}{c|}{ Critérios } & \multicolumn{1}{c}{ Descrição } \\
\hline 1 - Nome da fonte de informação & Identificação da fonte, nome da fonte. \\
\hline $\begin{array}{l}\text { 2 - Identificação do responsável ou } \\
\text { produtor }\end{array}$ & Dados do responsável; nome e endereço para contato. \\
\hline 3 - Conteúdo & $\begin{array}{l}\text { Breve descrição do conteúdo da fonte incluindo seu } \\
\text { escopo e cobertura. }\end{array}$ \\
\hline 4 - Aquisição & $\begin{array}{l}\text { Nome e endereço da instituição que disponibiliza a } \\
\text { fonte (que pode ou não ser a mesma que o produtor). }\end{array}$ \\
\hline 5 - Início da produção & $\begin{array}{l}\text { Data do início da produção da fonte em forma } \\
\text { eletrônica. }\end{array}$ \\
\hline 6 - Forma de disponibilização & Meio de disponibilização da fonte. \\
\hline 7 - Número de registros & $\begin{array}{l}\text { Quantidade de registros na fonte (por exemplos: } \\
\text { número de registros bibliográficos cadastrados). }\end{array}$ \\
\hline 8 - Cobertura tópica & Tipo de informação/assunto contida na fonte. \\
\hline 9 - Cobertura geográfica & $\begin{array}{l}\text { No caso da fonte cobrir vários assuntos, usou-se um } \\
\text { asterisco para indicar o assunto principal. }\end{array}$ \\
\hline 10 - Tempo de cobertura & $\begin{array}{l}\text { Período coberto pela fonte. Os tipos possíveis são; Data } \\
\text { de início e Data de término: indica que a fonte contém } \\
\text { documentos datados no intervalo. }\end{array}$ \\
\hline 11 - Frequência de atualização & Frequência com que os dados da fonte são atualizados. \\
\hline 12 - Serviços relacionados & Serviços fornecidos pela organização produtora a partir \\
\hline
\end{tabular}




\begin{tabular}{l|l}
\hline & $\begin{array}{l}\text { da fonte, como por exemplo, informações de outras } \\
\text { fontes/bases ou outros tipos de publicação. }\end{array}$ \\
\hline 13 - Outras observações & $\begin{array}{l}\text { Dados complementares sobre a fonte fornecidos pelo } \\
\text { produtor ou obtidos na Internet. }\end{array}$ \\
\hline 14 - Data da coleta de dados & $\begin{array}{l}\text { Data em que as informações sobre a fonte foram } \\
\text { obtidas. }\end{array}$ \\
\hline
\end{tabular}

Fonte: Adaptado de Cendón (2003).

\section{IDENTIFICAÇÃO E DESCRIÇÃO DAS FONTES DE INFORMAÇÃO}

As fontes de informação coletadas foram organizadas em quatro categorias denominadas: fontes de informação social e de humanidades; fontes de informação de finanças, estatística e indicadores econômicos; fontes de informação para o desenvolvimento ambiental sustentável e fontes de informação em saúde.

\section{Categoria 1 - Fontes de Informação Social e de Humanidades}

Foram encontradas 09 fontes contendo informações bibliográficas abrangentes e interdisciplinares relacionados a pesquisas, obras e publicações de africanos e sobre a África a respeito de: literatura, educação, história, geografia, notícias, sociedade, memória e cultura.

Quadro 02 - Dag Hammarskjöld Library

\begin{tabular}{l|l}
\hline \multicolumn{1}{c|}{ Critérios } & \multicolumn{1}{c}{ Descrição } \\
\hline 1 - Nome da fonte & Africa Resources - Dag Hammarskjold Library \\
\hline 2 - Identificação do responsável & $\begin{array}{l}\text { Diretório de informações sobre a África indexada na } \\
\text { Biblioteca das Organizações das Nações Unidas - ONU - } \\
\text { Estados Unidos. }\end{array}$ \\
\hline 3 - Conteúdo & $\begin{array}{l}\text { Fornece acesso a uma variedade de recursos relevantes para } \\
\text { qualquer pessoa interessada em fazer pesquisas sobre a } \\
\text { Âfrica. Conteúdos apresentados são: livros e publicações; } \\
\text { revistas e bancos de dados; e recursos multimídias. }\end{array}$ \\
\hline 4 - Aquisição & $\begin{array}{l}\text { Edifício da Biblioteca, Sala L-105 } \\
\text { Biblioteca das Nações Unidas Dag Hammarskjöld, }\end{array}$ \\
& $\begin{array}{l}\text { FirstAvenue na 42nd Street, Nova York, NY 10017, EUA. } \\
\text { Telefone: +1 (212) -963-3000 }\end{array}$ \\
\hline 5 - Início da produção & $\begin{array}{l}\text { A biblioteca Dag Hammarskjold teve início em 1961. Já o } \\
\text { diretório de pesquisa africana não apresenta essa informação } \\
\text { de data inicial de produção. }\end{array}$ \\
\hline 6 - Forma de disponibilização & Disponível em: https://research.un.org/en/africaresources \\
\hline 7 - Número de registros & Não especificado. \\
\hline
\end{tabular}




\begin{tabular}{l|l}
\hline 8 - Cobertura tópica & $\begin{array}{l}\text { Assuntos dos mais variados. Apresenta um recorte de } \\
\text { informações que englobam América Latina e Caribe, África, } \\
\text { Ásia e Pacífico. Além de temas relacionados à economia, } \\
\text { política e meio ambiente de países africanos. }\end{array}$ \\
\hline 9 - Cobertura geográfica & América Latina e Caribe, África, Ásia e Pacífico. \\
\hline 10 - Tempo de cobertura & Não especificado. \\
\hline 11 - Frequência de atualização & $\begin{array}{l}\text { Indefinido. A última atualização aparece na página como } \\
\text { sendo do dia 15 de janeiro de 2019, às 16 horas (Jan 15, } \\
\text { 2019 4:00 PM). }\end{array}$ \\
\hline 12 - Serviços relacionados & $\begin{array}{l}\text { Informações Estatísticas; Tesauros; Coleções históricas } \\
\text { Orais. }\end{array}$ \\
\hline 13 - Outras observações & $\begin{array}{l}\text { A biblioteca possui um total de 02 milhões de buscas e } \\
\text { pesquisas anual. }\end{array}$ \\
\hline 14 - Data da coleta de dados & 04 de março de 2019. \\
\hline
\end{tabular}

Fonte: Dados da pesquisa, 2018.

A Biblioteca Dag Hammarskjöld fornece acesso a um conjunto rico de recursos relevantes para qualquer pessoa interessada em fazer pesquisas na África. Neste diretório, foi compilada uma lista dos recursos mais populares, úteis e oficiais da África. Alguns recursos estão disponíveis gratuitamente e on-line, outros recursos são disponibilizados por meio de assinaturas, e os demais estão disponíveis na Biblioteca, dentro da sede da ONU, em Nova York.

Quadro 03 - Africa Wide Information

\begin{tabular}{l|l}
\hline \multicolumn{1}{c|}{ Critérios } & \multicolumn{1}{c}{ Descrição } \\
\hline 1 - Nome da fonte & Africa-Wide Information \\
\hline 2 - Identificação do responsável & EBSCO \\
\hline 3 - Conteúdo & $\begin{array}{l}\text { É um índice multidisciplinar para pesquisas e publicações } \\
\text { sobre a África. }\end{array}$ \\
\hline 4 - Aquisição & $\begin{array}{l}10 \text { Estes Street, Ipswich, MA 01938 } \\
\text { (978) 356 - 6500 }\end{array}$ \\
\hline 5 - Início da produção & Informação não disponível na fonte. \\
\hline 6 - Forma de disponibilização & $\begin{array}{l}\text { Disponível em: https://www.ebsco.com/products/research- } \\
\text { databases/africa-wide-information }\end{array}$ \\
\hline 7 - Número de registros & Não especificado. \\
\hline 8 - Cobertura tópica & $\begin{array}{l}\text { Assuntos relacionados a pesquisas acadêmicas de } \\
\text { pesquisadores africanos sobre a África. }\end{array}$ \\
\hline 9 - Cobertura geográfica & $\begin{array}{l}\text { Apresenta informações de pesquisadores africanos sobre a } \\
\text { África, Europa e América do Norte. }\end{array}$ \\
\hline 10 - Tempo de cobertura & Informação não disponível na fonte. \\
\hline 11 - Frequência de atualização & Atualizada em janeiro de 2019. \\
\hline 12 - Serviços relacionados & $\begin{array}{l}\text { Informações sobre bases de dados da Europa e América do } \\
\text { Norte. }\end{array}$ \\
\hline 13 - Outras observações & Não foi possível acessar algumas informações, pois é \\
\hline
\end{tabular}


Fonte: Dados da pesquisa, 2018

A Africa-Wide Information agrega 50 bancos de dados provenientes da África, Europa e América do Norte. Cobre quase 04 milhões de artigos de notícias, artigos de publicações acadêmicas, livros, relatórios, teses, citações e literatura cinza. Os registros incluem resumos de artigos e algum texto completo com indexação de palavras-chave para aprimorar a recuperação dos documentos.

Quadro 04 - Portal de Memórias de África e do Oriente

\begin{tabular}{l|l}
\hline \multicolumn{1}{c|}{ Critérios } & \multicolumn{1}{c}{ Descrição } \\
\hline 1 - Nome da fonte & Portal de Memórias de África e do Oriente \\
\hline 2 - Identificação do responsável & Universidade de Aveiro - Portugal \\
\hline 3 - Conteúdo & $\begin{array}{l}\text { É especializada em assuntos relacionados à memória } \\
\text { histórica dos laços entre Portugal e a Lusofonia. }\end{array}$ \\
\hline 4 - Aquisição & $\begin{array}{l}\text { Joaquim Sousa Pinto } \\
\text { Lurdes Tavares Gonçalves - Coordenadores, Universidade } \\
\text { de Aveiro - Portugal. }\end{array}$ \\
\hline 5 - Início da produção & Em formato eletrônico desde 2005. \\
\hline 6 - Forma de disponibilização & Disponível em: http://memoria-africa.ua.pt/ \\
\hline 7 - Número de registros & Mais de sete mil registros. \\
\hline 8 - Cobertura tópica & $\begin{array}{l}\text { Base de dados bibliográfica com orientação para a pesquisa. } \\
\text { Tem como principal objetivo a criação de um catálogo de } \\
\text { referências da memória dos conhecimentos em arquivo, } \\
\text { centros de documentação e bibliotecas. }\end{array}$ \\
\hline 9 - Cobertura geográfica & $\begin{array}{l}\text { Países africanos de Língua Oficial Portuguesa (PALOP) e da } \\
\text { Lusofonia em geral. }\end{array}$ \\
\hline 10 - Tempo de cobertura & Desde 2005 com endereço eletrônico. \\
\hline 11 - Frequência de atualização & Última atualização foi em janeiro de 2019. \\
\hline 12 - Serviços relacionados & Memória, cultura, história e língua portuguesa. \\
\hline 13 - Outras observações & $\begin{array}{l}\text { A base apresenta uma vasta coleção em língua portuguesa da } \\
\text { memória de países africanos com idioma português. }\end{array}$ \\
\hline 14 - Data da coleta de dados & 05 de março de 2019. \\
\hline Fo
\end{tabular}

Fonte: Dados da pesquisa, 2018.

O Portal das Memórias de África e do Oriente oferece um catálogo que reúne referências de arquivos, centros de documentação, bibliotecas e documentos de instituições relacionadas com a temática de desenvolvimento e cooperação com os países africanos de 
língua portuguesa e da lusofonia em geral. Através de uma biblioteca e um arquivo digital, disponibiliza-se online e livre acesso referências bibliográficas de várias partes do mundo.

Quadro 05 - Slave Voyages

\begin{tabular}{|c|c|}
\hline Critérios & Descrição \\
\hline 1 - Nome da fonte & Slave Voyages - Banco de Dados do Tráfico de Escravos \\
\hline 2 - Identificação do responsável & Instituto Hutchins da Universidade de Havard - EUA. \\
\hline 3 - Conteúdo & $\begin{array}{l}\text { É especializada em documentos relacionados ao tráfico } \\
\text { negreiro no mundo. }\end{array}$ \\
\hline $4-$ Aquisição & e-mail: voyages@emory.edu \\
\hline 5 - Início da produção & $\begin{array}{l}\text { O projeto de pesquisa teve início em 1990, com o objetivo } \\
\text { de reunir documentos referentes ao tráfico negreiro em um } \\
\text { único conjunto de dados. }\end{array}$ \\
\hline 6 - Forma de disponibilização & Disponível em: https://www.slavevoyages.org/about/about \\
\hline 7 - Número de registros & $\begin{array}{l}\text { Disponibiliza } 91.491 \text { registros pessoais de Africanos. } \\
\text { Antes, esses dados eram registrados em CDs. A partir de } \\
2003 \text { passou para o formato eletrônico. }\end{array}$ \\
\hline 8 - Cobertura tópica & $\begin{array}{l}\text { Assuntos relacionados ao tráfico negreiro reunidos em } \\
\text { documentos e arquivos através de dados de pesquisadores } \\
\text { sobre o tema. }\end{array}$ \\
\hline 9 - Cobertura geográfica & $\begin{array}{l}\text { Os principais acervos explorados foram os de Luanda, Rio } \\
\text { de Janeiro, Bahia, Lisboa, Havana, Madri, Sevilha, } \\
\text { Amsterdã, Midelburgo, Copenhague e Londres. }\end{array}$ \\
\hline 10 - Tempo de cobertura & Não disponível na fonte. \\
\hline 11 - Frequência de atualização & Atualizada em janeiro de 2019. \\
\hline 12 - Serviços relacionados & $\begin{array}{l}\text { Banco de dados do trafico negreiro marítimo, fotos de } \\
\text { documentos originais com dados pessoais dos escravizados. }\end{array}$ \\
\hline 13 - Outras observações & Indexada pela Capes. \\
\hline 14 - Data da coleta de dados & 05 de março de 2019. \\
\hline
\end{tabular}

Fonte: Dados da pesquisa, 2018.

O Slave Voyages é o resultado de várias décadas de pesquisas independentes e colaborativas, com base em dados encontrados em bibliotecas e arquivos de todo o mundo atlântico. Este memorial digital levanta questões sobre o maior comércio de escravos da história e oferece acesso à documentação disponível para respondê-las. 
Quadro 06 - Centro de Estudos Africanos

\begin{tabular}{l|l}
\hline \multicolumn{1}{c|}{ Critérios } & \multicolumn{1}{c}{ Descrição } \\
\hline 1 - Nome da fonte & Centro de Estudos Africanos - UFMG. \\
\hline 2 - Identificação do responsável & Vinculado à Diretoria de Relações Internacionais da UFMG. \\
\hline 3 - Conteúdo & $\begin{array}{l}\text { Acervo bibliográfico formado com obras produzidas por } \\
\text { africanos, em continente africano ou em outras partes do } \\
\text { mundo. Privilegia o ponto de vista africano sobre quaisquer } \\
\text { aspectos daquele continente. }\end{array}$ \\
\hline 4- Aquisição & $\begin{array}{l}\text { Acervo comprado com recursos públicos e, também, obtidos } \\
\text { por doação de livreiros, pesquisadores, distribuidores de } \\
\text { países africanos. }\end{array}$ \\
\hline 5 - Início da produção & Suas atividades tiveram início em 2012. \\
\hline 6 - Forma de disponibilização & $\begin{array}{l}\text { Disponível em: } \text { https://www.ufmg.br/dri/centros-de- } \\
\text { internacionalizacao-e-redes/centro-de-estudos-africanos/ }\end{array}$ \\
\hline 7 - Número de registros & Aproximadamente 03 mil obras. \\
\hline 8 - Cobertura tópica & Todas as áreas do conhecimento. \\
\hline 10 - Cobertura geográfica & $\begin{array}{l}\text { Apresenta informações de países da África e de pesquisas } \\
\text { realizadas no Brasil sobre temas africanos. }\end{array}$ \\
\hline 11 - Frequência de atualização & Desde 2012, com endereço eletrônico. \\
\hline 12 - Serviços relacionados & $\begin{array}{l}\text { Atualizado. A última atualização foi em Janeiro de 2019. } \\
\text { Congregar pesquisadores, da UFMG e de outras Instituições } \\
\text { de Ensino Superior que desenvolvam pesquisas pertinentes à } \\
\text { África, ou pesquisas realizadas com a participação de } \\
\text { pesquisadores africanos. }\end{array}$ \\
\hline 13 - Outras observações & $\begin{array}{l}\text { O Centro oferece mostra de cinema de países africanos; } \\
\text { Minicursos; Conferências; Músicas e palestras todos } \\
\text { relacionados com a cultura africana. Além de editorar a Série } \\
\text { (registrada na Biblioteca Nacional brasileira) "Estudos do } \\
\text { Africanos do CEA/UFMG)". }\end{array}$ \\
\hline 09 de março de 2019. \\
\hline
\end{tabular}

Fonte: Dados da pesquisa, 2018.

O Centro de Estudos Africanos da UFMG mantém um acervo de obras produzidas, prioritariamente, por autores e editores africanos e afro-americanos. As obras têm sido adquiridas pelo Centro de Estudos Africanos/UFMG em diferentes países da África, como Angola, Moçambique, Guiné-Bissau e Cabo Verde, e também da América, como Colômbia. Trata-se de acervo único no Brasil, que pretende servir como referência para pesquisadores interessados na história da África e da diáspora. 
QUADRO 07 - Coleção História Geral da África - Programa Brasil-África

\begin{tabular}{|c|c|}
\hline Critérios & Descrição \\
\hline 1 - Nome da fonte & Coleção História Geral da África \\
\hline 2 -Identificação do responsável & $\begin{array}{l}\text { Programa Brasil-África: Histórias Cruzadas - UNESCO/ } \\
\text { Brasília. }\end{array}$ \\
\hline 3-Conteúdo & $\begin{array}{l}\text { Publicada em oito volumes. Permite compreender o } \\
\text { desenvolvimento histórico dos povos africanos e sua relação } \\
\text { com outras civilizações a partir de uma visão panorâmica, } \\
\text { diacrônica e objetiva, obtida de dentro do continente. }\end{array}$ \\
\hline $4-$ Aquisição & $\begin{array}{l}\text { Brasília: UNESCO, Secad/MEC, UFSCar, 2010. (Somente } \\
\text { em PDF para download). }\end{array}$ \\
\hline 5 - Início da produção & $\begin{array}{l}\text { A obra, em sua tradução para o português, foi lançada em } \\
2010 \text {. }\end{array}$ \\
\hline 6 - Forma de disponibilização & $\begin{array}{l}\text { Disponível em: http://www.unesco.org/new/pt/brasilia/about- } \\
\text { this- } \\
\text { office/singleview/news/general_history_of_africa_collection } \\
\text { in_portuguese_pdf_only/ }\end{array}$ \\
\hline 7 - Número de registros & $\begin{array}{l}\text { São oito volumes. } \\
\text { Volume I - metodologia e pré-história da África. ISBN: 978- } \\
\text { 85-7652-123-5. Número de páginas: } 990 . \\
\text { Volume II - África antiga. ISBN: 978-85-7652-124-2. } \\
\text { Número de páginas: 1006. } \\
\text { Volume III - África do século VII ao XI. ISBN: 978-85- } \\
\text { 7652-125-9. Número de páginas: } 1054 \text {. } \\
\text { Volume IV - África do século XII ao XVI. ISBN: 978-85- } \\
\text { 7652-126-6. Número de páginas: 892. } \\
\text { Volume V - África do século XVI ao XVIII. ISBN: 978-85- } \\
\text { 7652-127-3. Número de páginas: } 1208 \text {. } \\
\text { Volume VI - África do século XIX à década de 1880. ISBN: } \\
\text { 978-85-7652-128-0. Número de páginas: } 1034 . \\
\text { Volume VII - África sob dominação colonial, 1880-1935. } \\
\text { ISBN: 978-85-7652-129-7. Número de páginas: 1040. } \\
\text { Volume VIII - África desde 1935. ISBN: } 978-85-7652-130- \\
\text { 3. Número de páginas: } 1273 \text {. }\end{array}$ \\
\hline 8 - Cobertura tópica & Assuntos relacionados a temas gerais de história da África. \\
\hline 9 - Cobertura geográfica & O continente e, quando necessário, aborda sua diáspora. \\
\hline 10 - Tempo de cobertura & Desde a pré-história até a contemporaneidade do continente. \\
\hline 11 - Frequência de atualização & Indefinido. \\
\hline 12 - Serviços relacionados & $\begin{array}{l}\text { A fonte apresenta links para fazer o download dos volumes } \\
\text { completos da obra gratuitamente. }\end{array}$ \\
\hline 13 - Outras observações & $\begin{array}{l}\text { Foi produzida por mais de } 350 \text { especialistas das mais } \\
\text { variadas áreas do conhecimento, sob a direção de um Comitê } \\
\text { Científico Internacional formado por } 39 \text { intelectuais, dos } \\
\text { quais dois terços eram africanos. Cita-se, por exemplo, a } \\
\text { professora Dra., brasileira, Vanicléia Silva Santos, da } \\
\text { UFMG, que integra o Comitê Científico Internacional da } \\
\text { Unesco para elaboração do IX volume da HGA. }\end{array}$ \\
\hline 14 - Data da coleta de dados & 09 de março de 2019. \\
\hline
\end{tabular}

Fonte: Dados da pesquisa, 2018. 
A coleção História Geral da África está disponível em língua portuguesa, além de já ter sido publicada nas línguas árabe, inglesa e francesa. Um dos projetos editoriais mais importantes da UNESCO nos últimos trinta anos, a coleção História Geral da África é um grande marco no processo de reconhecimento do patrimônio cultural da África. A coleção foi produzida por mais de 350 especialistas das mais variadas áreas do conhecimento, sob a direção de um Comitê Científico Internacional formado por 39 intelectuais, dos quais dois terços eram africanos.

Quadro 08 - African Online Journals

\begin{tabular}{|c|c|}
\hline Critérios & Descrição \\
\hline 1 - Nome da fonte & African Online Journals (AJOL) \\
\hline 2 - Identificação do responsável & African Online Journals (AJOL) - África do Sul. \\
\hline 3 -Conteúdo & $\begin{array}{l}\text { A AJOL é o único banco de dados online que hospeda } \\
\text { periódicos de todos os países da África. }\end{array}$ \\
\hline 4-Aquisição & Não especificado. \\
\hline 5 - Início da produção & Início em 1998. \\
\hline 6 - Forma de disponibilização & Disponível em: https://www.ajol.info/ \\
\hline 7 - Número de registros & $\begin{array}{l}523 \text { periódicos de } 32 \text { países da África. Mais de } 18.000 \\
\text { resumos de artigos. }\end{array}$ \\
\hline 8 - Cobertura tópica & $\begin{array}{l}\text { Assuntos relacionados a pesquisas desenvolvidas na } \\
\text { África para pesquisadores africanos e demais } \\
\text { pesquisadores. }\end{array}$ \\
\hline 9 - Cobertura geográfica & $\begin{array}{l}\text { Trabalhos relacionados à África do Sul. Indexa periódicos } \\
\text { de } 32 \text { países da África. }\end{array}$ \\
\hline 10 - Tempo de cobertura & Desde 2005 com endereço eletrônico. \\
\hline 11 - Frequência de atualização & Última atualização foi em janeiro de 2019. \\
\hline 12 - Serviços relacionados & $\begin{array}{l}\text { Possui ferramenta de busca avançada. Existem abas para } \\
\text { pesquisadores, para bibliotecários e autores, além de um } \\
\text { tutorial. }\end{array}$ \\
\hline 13 - Outras observações & $\begin{array}{l}\text { Existem ainda mais de } 164.339 \text { textos completos para } \\
\text { downloads dos quais } 105 \text { mil possuem acesso aberto. }\end{array}$ \\
\hline 14 - Data da coleta de dados & 18 de março de 2019. \\
\hline
\end{tabular}

Fonte: Dados da pesquisa, 2018.

A African Online Journals (AJOL) é a maior coleção online do mundo de periódicos acadêmicos, publicados pela África e revisados por pares. Sua missão é aumentar a visibilidade online, acesso e uso da produção científica publicada na África em apoio à pesquisa africana de qualidade e ao ensino superior. A AJOL fornece hospedagem online gratuita para mais de 500 periódicos revisados por pares de 31 países africanos. Mais da 
metade dos 100.000 artigos em texto completo no site estão em parceiros de periódicos de acesso aberto e podem ser baixados gratuitamente.

Quadro 09 - African American Biographical Database

\begin{tabular}{|c|c|}
\hline Critérios & Descrição \\
\hline 1 - Nome da fonte & African American Biographical Database (AABD) \\
\hline 2 - Identificação do responsável & Biblioteca da Universidade de Delaware - Estados Unidos. \\
\hline 3 - Conteúdo & $\begin{array}{l}\text { Reúne as biografias de milhares de afro-americanos. Estes esboços } \\
\text { biográficos foram montados a partir de dicionários biográficos e } \\
\text { outras fontes. }\end{array}$ \\
\hline 4 - Aquisição & $\begin{array}{l}\text { Biblioteca da Universidade de Delaware } \\
181 \text { South College Avenue } \\
\text { Newark, DE 19717-5267 - (302) 831-2965. }\end{array}$ \\
\hline 5 - Início da produção & Não especificado. \\
\hline 6 - Forma de disponibilização & Disponível em: https://library.udel.edu/databases/aabd/ \\
\hline 7 - Número de registros & $\begin{array}{l}\text { Não especificado. Foram analisados documentos bibliográficos de } \\
1790 \text { a } 1950 \text {. }\end{array}$ \\
\hline 8 - Cobertura tópica & $\begin{array}{l}\text { A coleção contém narrativas de ativistas afro-americanos, } \\
\text { empresários, ex-escravizados, artistas, educadores, advogados, } \\
\text { médicos, escritores, líderes de igrejas, donas de casa, trabalhadores } \\
\text { religiosos, funcionários do governo, atletas, agricultores, cientistas, } \\
\text { operários e pessoas famosas. }\end{array}$ \\
\hline 9 - Cobertura geográfica & $\begin{array}{l}\text { Uma coleção de narrativas de afro-americanos para afro- } \\
\text { americanos e demais interessados. }\end{array}$ \\
\hline 10 - Tempo de cobertura & Não especificado. \\
\hline 11 - Frequência de atualização & Última atualização foi em 2019. \\
\hline 12 - Serviços relacionados & $\begin{array}{l}\text { Links de bibliotecas e museus, horários de funcionamento } \\
\text { disponível no site. }\end{array}$ \\
\hline 13 - Outras observações & $\begin{array}{l}\text { Quatro coleções especiais e museus. Os espaços da galeria } \\
\text { incluem: Mechanical Hall, Museu Mineralogico em Penny Hall, } \\
\text { Old College Gallery e a Galeria de coleções Especiais na } \\
\text { Biblioteca Morris. }\end{array}$ \\
\hline 14 - Data da coleta de dados & 18 de março de 2019. \\
\hline
\end{tabular}

Fonte: Dados da pesquisa, 2018.

O African American Biographical Database (1790-1950) é uma coleção eletrônica exclusiva de informações biográficas sobre afro-americanos, com mais de 40.000 itens de mais de 290 títulos. Do famoso ao cotidiano, o banco de dados inclui perfis e esboços de texto completo, fornecendo detalhes biográficos e narrativos que descrevem a vida dos negros americanos. Cada texto usado no banco de dados biográfico afro-americano foi totalmente digitalizado para que, além de procurar esboços biográficos específicos, seja possível o acesso direto a uma rica coleção de obras de referência afro-americanas, muitas das quais são obras raras. 
Quadro 10 - African Education Research Database

\begin{tabular}{l|l}
\hline \multicolumn{1}{c|}{ Critérios } & \multicolumn{1}{c}{ Descrição } \\
\hline 1 - Nome da fonte & African Education Research Database \\
\hline 2 - Identificação do responsável & $\begin{array}{l}\text { Faculdade de Educação da Universidade de Cambridge - } \\
\text { Inglaterra. }\end{array}$ \\
\hline 3 - Conteúdo & $\begin{array}{l}\text { O Banco de Dados Africano de Pesquisa Educacional foi } \\
\text { desenvolvido pelo Centro de Pesquisa para Equidade de } \\
\text { Acesso e Aprendizagem (REAL), para se juntar, informar, } \\
\text { inspirar, focar e aumentar o impacto para todos que investem } \\
\text { em educação na África Subsaariana. }\end{array}$ \\
\hline 4- Aquisição & Apresenta janela para assinaturas. \\
\hline 5 - Início da produção & Suas atividades tiveram início em 2016. \\
\hline 6- Forma de disponibilização & Disponível em: https://essa-africa.org/AERD \\
\hline - Número de registros & Mais de 3.000 itens para pesquisa. \\
\hline 9 - Cobertura tópica & $\begin{array}{l}\text { Assuntos relacionados à educação voltada a países da África } \\
\text { Subsaariana, apoiando os Objetivos de Desenvolvimento } \\
\text { Sustentável (ODS). }\end{array}$ \\
\hline 10 - Tempo de cobertura & $\begin{array}{l}\text { Cobre países da África Subsaariana. É um banco de dados } \\
\text { com informaçóes para estudantes ingleses sobre a educação } \\
\text { desses países da África. }\end{array}$ \\
\hline 11 - Frequência de atualização & Desde 2016 com endereço eletrônico. \\
\hline 12 - Serviços relacionados & Não identificada. \\
\hline 13 - Outras observações & A fontentificado. \\
\hline 14 - Data da coleta de dados & 18 de março de 2019. \\
\hline
\end{tabular}

Fonte: Dados da pesquisa, 2018.

O African Education Research Database foi criado como um banco de dados sobre a educação da África Subsaariana para facilitar o acesso a esse tipo de conteúdo e para os pesquisadores africanos publicarem seus trabalhos. O banco de dados inclui pesquisa em ciências sociais direcionada para a política e a prática educacional. Possui artigos revisados por pares, capítulos, teses e documentos identificados por meio de pesquisas estruturadas em bancos de dados acadêmicos e de literatura cinzenta.

\section{Categoria 2 - Fontes de Informação de Finanças, Estatística e Indicadores Econômicos}

Foram encontradas 04 fontes de informação relacionadas às temáticas: finanças, estatísticas e indicadores econômicos, contendo literatura sobre mercados, negócios, estatísticas de negócios, indicadores mercadológicos e ciência. 
Quadro 11 - African Business Guide - Library of Congress

\begin{tabular}{l|l}
\hline \multicolumn{1}{c|}{ Critérios } & \multicolumn{1}{c}{ Descrição } \\
\hline 1 - Nome da fonte & \multicolumn{1}{c}{ African Business Guide - Library of Congress } \\
\hline 2 - Identificação do responsável & $\begin{array}{l}\text { Biblioteca do Congresso de Washington - Estados } \\
\text { Unidos. }\end{array}$ \\
\hline 3 - Conteúdo & $\begin{array}{l}\text { É especializada em assuntos relacionados a negócios, } \\
\text { mercados, investimentos e bancos. }\end{array}$ \\
\hline 4 - Aquisição & $\begin{array}{l}202707 \text { 1925 } \\
\text { Science, Technology e Business Division Business } \\
\text { Reference Services. } \\
\text { Library of Congress Washington, D. C. 20540 - 4754 }\end{array}$ \\
\hline 5 - Início da produção & Suas atividades tiveram início em 2010. \\
\hline 6 - Forma de disponibilização & $\begin{array}{l}\text { Disponível } \\
\text { http://www.loc.gov/rr/business/african/databases.html }\end{array}$ \\
\hline 7 - Número de registros & Não especificado. \\
\hline 8 - Cobertura tópica & $\begin{array}{l}\text { Assuntos relacionados a temas como: boletins } \\
\text { informativos de investimentos e comércio em 48 países } \\
\text { africanos; Serviços de informações e negócios africanos; } \\
\text { oportunidades globais de negócios; Redes de promoção; } \\
\text { Bancos de desenvolvimento e etc. }\end{array}$ \\
\hline 9 - Cobertura geográfica & $\begin{array}{l}\text { Apresenta informações de países da África subsaariana, } \\
\text { regiões da Ásia, Oriente Médio, Europa, América Latina. }\end{array}$ \\
\hline 10 - Tempo de cobertura & Desde 2010 com endereço eletrônico. \\
\hline 11 - Frequência de atualização & A última atualização foi em 20 de maio de 2015. \\
\hline 12 - Serviços relacionados & $\begin{array}{l}\text { Negócios, investimentos e comércio voltados ao mercado } \\
\text { de países africanos. }\end{array}$ \\
\hline 13 - Outras observações & $\begin{array}{l}\text { Alguns links indexados referentes a departamentos } \\
\text { econômicos deixaram de existir desde setembro de 2010. }\end{array}$ \\
\hline 14 - Data da coleta de dados & 04 de março de 2019. \\
\hline
\end{tabular}

Fonte: Dados da pesquisa, 2018.

O African Business Guide concentra em fornecer acesso a uma coleção de recursos online de informações comerciais e financeiras africanas, principalmente no nível continental ou específico da região. A cobertura inclui diretórios gerais de negócios focados em informações sobre comércio internacional, financeiro, jurídico e de mercado, análise do setor, dados econômicos e estatísticos básicos do país, notícias de negócios e do setor, bolsas de valores e moedas e jornais especializados.

Quadro 12 - DataBank Africa- The World Bank

\begin{tabular}{l|l}
\hline \multicolumn{1}{c|}{ Critérios } & \multicolumn{1}{c}{ Descrição } \\
\hline 1 - Nome da fonte & DataBank Africa - The World Bank \\
\hline 2 - Identificação do responsável & Banco Mundial - Estados Unidos. \\
\hline 3- Conteúdo & É especializada em informações estatísticas disponíveis em \\
\hline
\end{tabular}




\begin{tabular}{l|l}
\hline & um único volume sobre indicadores de desenvolvimento. \\
\hline 4 - Aquisição & The World Bank. \\
\hline 5 - Início da produção & $\begin{array}{l}\text { O volume foi elaborado em 2013. O recorte é de 1960 a } \\
\text { 2011. }\end{array}$ \\
\hline 6 - Forma de disponibilização & $\begin{array}{l}\text { Disponível } \\
\text { https://databank.worldbank.org/databases/africa }\end{array}$ \\
\hline 7 - Número de registros & Indefinido. \\
\hline 8 - Cobertura tópica & $\begin{array}{l}\text { Assuntos relacionados a temas e indicadores estatísticos de } \\
\text { desenvolvimento macroeconômico, setorial e social, } \\
\text { abrangendo 53 países africanos 1960 até 2011. }\end{array}$ \\
\hline 9 - Cobertura geográfica & $\begin{array}{l}\text { Apresenta informações referentes a indicadores de } \\
\text { desenvolvimento social de 53 países abrangendo mais de } \\
1.700 \text { indicadores. }\end{array}$ \\
\hline 10 - Tempo de cobertura & A partir de 1960 até 2011. \\
\hline 11 - Frequência de atualização & A última atualização foi em 22 de fevereiro de 2013. \\
\hline 12 - Serviços relacionados & $\begin{array}{l}\text { Indicadores de pobreza, educação e desenvolvimento social } \\
\text { da África. }\end{array}$ \\
\hline 13 - Outras observações & $\begin{array}{l}\text { AfricaDataFinder está disponível para iTunes e no Google } \\
\text { Play. }\end{array}$ \\
\hline 14 - Data da coleta de dados & 04 de março de 2019. \\
\hline Fonte Dados da pesquis, 2018 &
\end{tabular}

Fonte: Dados da pesquisa, 2018.

O Africa Development Indicators fornece um conjunto detalhado de dados sobre a África. Contém indicadores macroeconômicos, setoriais e sociais de 53 países africanos. Foi projetado para fornecer um conjunto confiável de dados sobre programas de desenvolvimento e fluxos de suporte na região. É uma ferramenta de referência inestimável para analistas e formuladores de políticas que desejam uma melhor compreensão dos desenvolvimentos econômicos e sociais que ocorrem na África.

Quadro 13 - Council for Scientific and Industrial Research

\begin{tabular}{|c|c|}
\hline Critérios & Descrição \\
\hline 1 - Nome da fonte & Council for Scientific and Industrial Research (CSIR) \\
\hline 2 - Identificação do responsável & Biblioteca Mann da Universidade de Cornell, Ithaca, NY. \\
\hline 3-Conteúdo & $\begin{array}{l}\text { O Conselho de Pesquisas Científicas e Industriais (CSIR) é } \\
\text { uma organização de pesquisa e desenvolvimento africana de } \\
\text { classe mundial estabelecida através de uma Lei do } \\
\text { Parlamento em } 1945 \text { e a autoridade executiva da organização } \\
\text { é o Ministro da Ciência e Tecnologia dos EUA. }\end{array}$ \\
\hline $4-$ Aquisição & $\begin{array}{l}\text { Tel: + } 27128412911 \\
\text { E-mail: enriques @ csir.co.za } \\
\text { Endereço: MeiringNaudé Road } \\
\text { Brumeria- Pretoria- África do Sul }\end{array}$ \\
\hline 5 - Início da produção & Suas atividades tiveram início em 1945. \\
\hline
\end{tabular}




\begin{tabular}{l|l}
\hline 6 - Forma de disponibilização & Disponível em: https://www.csir.co.za/ \\
\hline 7 - Número de registros & Não informado. \\
\hline 8 - Cobertura tópica & $\begin{array}{l}\text { Realiza pesquisa multidisciplinar direcionada e inovação } \\
\text { tecnológica com foco na população sul-africana, voltada ao } \\
\text { desempenho no apoio aos programas do governo por meio de } \\
\text { pesquisa direcionada que esteja alinhada com as prioridades } \\
\text { do país, o mandato da organização e suas competências em } \\
\text { ciência, engenharia e tecnologia. }\end{array}$ \\
\hline 9 - Cobertura geográfica & África do Sul. \\
\hline 10 - Tempo de cobertura & Não informado. \\
\hline 11 - Frequência de atualização & Última atualização foi em 2019. \\
\hline 13 - Outras observações & $\begin{array}{l}\text { Link “Trabalhe conosco" disponível para preenchimento e } \\
\text { envio de currículos. }\end{array}$ \\
\hline 14 - Data da coleta de dados & $\begin{array}{l}\text { Disponibiliza informações relacionadas a eventos da área; } \\
\text { galeria multimídia; publicações; pesquisa e desenvolvimento. }\end{array}$ \\
\hline
\end{tabular}

Fonte: Dados da pesquisa, 2018.

O Council for Scientific and Industrial Research (CSIR) é uma organização líder em pesquisa científica e tecnológica que desenvolve, localiza e difunde informações tecnológicas para acelerar a uma perspectiva de prosperidade socioeconômica na África do Sul. Desempenha um papel fundamental no apoio aos setores público e privado por meio de pesquisas direcionadas e alinhadas às prioridades do país.

Quadro 14 - Index to South African Periodicals

\begin{tabular}{l|l}
\hline \multicolumn{1}{c|}{ Critérios } & \multicolumn{1}{c}{ Descrição } \\
\hline 1 - Nome da fonte & Index to South African Periodicals (Sabinet) \\
\hline 2 - Identificação do responsável & Indexado pela Biblioteca Nacional da África do Sul. \\
\hline 3 - Conteúdo & $\begin{array}{l}\text { Artigos de revistas sul-africanas. O ISAP abrange artigos } \\
\text { indexados de periódicos sul-africanos. Os periódicos } \\
\text { especializados são indexados por completo, enquanto os } \\
\text { periódicos gerais e populares são indexados seletivamente. }\end{array}$ \\
\hline 4 - Aquisição & $\begin{array}{l}\text { E-mail: info@ sabinet.co.za } \\
\text { Serviços ao Cliente: +27 12 643 9500 }\end{array}$ \\
\hline 5 - Início da produção & Suas atividades tiveram início em 2012. \\
\hline 6- Forma de disponibilização & Disponível em: https://reference.sabinet.co.za/ \\
\hline 7 - Número de registros & Mais de 900 periódicos indexados. \\
\hline 8 - Cobertura tópica & $\begin{array}{l}\text { Assuntos referentes a trabalhos especializados e temas gerais } \\
\text { sul-africanos. }\end{array}$ \\
\hline 9 - Cobertura geográfica & África do Sul. \\
\hline 10 - Tempo de cobertura & Não especificado. \\
\hline 11 - Frequência de atualização & Última atualização foi em 2019. \\
\hline 12 - Serviços relacionados & $\begin{array}{l}\text { Digitalização de documentos; Consultoria e serviços para } \\
\text { bibliotecas. }\end{array}$ \\
\hline
\end{tabular}




\begin{tabular}{l|l}
\hline 13 - Outras observações & $\begin{array}{l}\text { Os serviços oferecidos são semelhantes à oferta de serviços } \\
\text { de empresas voltadas a digitalização e consultoria de } \\
\text { unidades de informação. Existe um termo de serviço e } \\
\text { apenas os jornais gerais são oferecidos gratuitamente. }\end{array}$ \\
\hline 14 - Data da coleta de dados & 18 de março de 2019. \\
\hline
\end{tabular}

Fonte: Dados da pesquisa, 2018.

O Index to South African Periodicals cobre artigos indexados de mais de 900 periódicos sul-africanos. Os artigos publicados nesses periódicos são uma fonte importante de dados recentes. Esse índice fornece o acesso aos periódicos de qualidade, em uma variedade de formatos, para divulgar a pesquisa, apoiar o ensino e a aprendizagem da University of Fort Hare.

\section{Categoria 3 - Fontes de Informação para o Desenvolvimento Ambiental Sustentável}

Foram encontradas 05 fontes de informação relacionadas a essa temática. As informações para o desenvolvimento ambiental sustentável tratam sobre agricultura, geografia, biologia, clima, plantas, e etc.

Quadro 15 - The Nordic Africa Institute

\begin{tabular}{|c|c|}
\hline Critérios & Descrição \\
\hline 1 - Nome da fonte & The Nordic Africa Institute \\
\hline 2 - Identificação do responsável & The Nordic Africa Institute - Suécia. \\
\hline 3 - Conteúdo & $\begin{array}{l}\text { É especializada em assuntos da África contemporânea, } \\
\text { campo das ciências sociais e algumas disciplinas artísticas. } \\
\text { Apresenta informações de todos os países do continente } \\
\text { africano e destina-se a usuários em toda região nórdica. }\end{array}$ \\
\hline 4- Aquisição & $\begin{array}{l}\text { nai@nai.uu.se } \\
(+46) 184715200 \\
\text { Villayagen } 6 \text { SE - } 75236 \text { Uppsala }\end{array}$ \\
\hline 5 - Início da produção & As atividades da biblioteca tiveram início em 2016. \\
\hline 6 - Forma de disponibilização & Disponível em: https://nai.uu.se/library/about/ \\
\hline 7 - Número de registros & Não especificado. \\
\hline 8 - Cobertura tópica & $\begin{array}{l}\text { Assuntos relacionados a temas como: Crescimento } \\
\text { econômico e desafios da pobreza; Mudança climática e } \\
\text { desenvolvimento sustentável; Conflito, segurança e } \\
\text { transformação democrática; Mobilidade e migração. }\end{array}$ \\
\hline 9 - Cobertura geográfica & O continente africano. \\
\hline 10 - Tempo de cobertura & $\begin{array}{l}\text { Desde } 2016 \text { com endereço eletrônico ( } 03 \text { anos). A biblioteca } \\
\text { física funciona de segunda a quinta-feira das } 10 \mathrm{~h} \text { às } 17 \mathrm{~h} \text {. }\end{array}$ \\
\hline 11 - Frequência de atualização & A última atualização foi em janeiro de 2019. \\
\hline
\end{tabular}




\begin{tabular}{l|l}
\hline 12 - Serviços relacionados & $\begin{array}{l}\text { Disponibiliza ferramenta de pesquisa como o aplicativo } \\
\text { AfricaLitPlus; e Links de coleções como um guia para a } \\
\text { África na Internet; Pdf com doações para acessar e } \\
\text { download gratuito. }\end{array}$ \\
\hline 13 - Outras observações & $\begin{array}{l}\text { Oferece um programa de bolsas de estudos com o objetivo } \\
\text { de promover e estabelecer relações de pesquisas entre } \\
\text { comunidades de pesquisa africanas e nórdicas. Os } \\
\text { programas de bolsas são voltados para pesquisadores de } \\
\text { pós-doutorado com pesquisas orientadas para a África } \\
\text { dentro das disciplinas de Ciências Sociais e Humanas. }\end{array}$ \\
\hline 14 - Data da coleta de dados & 04 de março de 2019. \\
\hline
\end{tabular}

Fonte: Dados da pesquisa, 2018.

A biblioteca da The Nordic Africa Institute é especializada e disponiliza obras direcionada ao campo das ciências sociais e de algumas disciplinas artísticas sobre a África Contemporânea. A coleção é composta por mais de 70.000 títulos em política, economia, história contemporânea, antropologia, literatura, ficção africana moderna, literatura de referência, jornais, revistas, livros eletrônicos, publicações oficiais, atlas e mapas.

Quadro 16 - The Essential Electronic Agriculture Library

\begin{tabular}{l|l}
\hline \multicolumn{1}{c|}{ Critérios } & \multicolumn{1}{c}{ Descrição } \\
\hline 1 - Nome da fonte & The Essential Electronic Agriculture Library (TEEAL) \\
\hline 2 - Identificação do responsável & Biblioteca Mann da Universidade de Cornell, Ithaca, NY. \\
\hline 3- Conteúdo & $\begin{array}{l}\text { É um banco de dados de texto completo e pesquisável de } \\
\text { artigos de mais de 450 revistas. }\end{array}$ \\
\hline 4- Aquisição & $\begin{array}{l}\text { teeal@ cornell.edu } \\
\text { Albert R. Mann Biblioteca da Universidade Cornell, Ithaca, } \\
\text { NY 14853 }\end{array}$ \\
\hline 5 - Início da produção & Suas atividades tiveram início em 2012. \\
\hline 6 - Forma de disponibilização & Disponível em: https://teeal.org/ \\
\hline - Número de registros & Mais de 450 revistas indexadas. \\
\hline - Cobertura tópica & $\begin{array}{l}\text { Assuntos relacionados a pesquisas agrícolas. Inclusive de } \\
\text { periódicos do continente africano. }\end{array}$ \\
\hline - Cobertura geográfica & $\begin{array}{l}\text { Uma biblioteca digital que contém principalmente revistas } \\
\text { voltadas para a agricultura e entregues pelo Escritório do } \\
\text { Projeto TEEAL na Biblioteca Mann da Universidade de } \\
\text { Cornell. }\end{array}$ \\
\hline 10 - Tempo de cobertura & Desde 2014, com endereço eletrônico. \\
\hline 11 - Frequência de atualização & Última atualização foi em 2019. \\
\hline 12 - Serviços relacionados & $\begin{array}{l}\text { Tutorial explicando como usar a fonte e oferece suporte } \\
\text { técnico aos usuários. }\end{array}$ \\
\hline 13 - Outras observações & Interface amigável. \\
\hline 14 - Data da coleta de dados & 18 de março de 2019. \\
\hline
\end{tabular}

Fonte: Dados da pesquisa, 2018. 
O The Essential Electronic Agricultural Library (TEEAL) é uma biblioteca digital que contém principalmente artigos disponibilizados em texto completo, focados na agricultura e nas ciências relacionadas a diversas regiões do mundo, dentre essas a África. Os títulos dos periódicos do TEEAL são considerados essenciais para a pesquisa e a educação de países em desenvolvimento. Os periódicos foram selecionados por análise de citação e revisados por cerca de 600 pesquisadores em todo o mundo.

Quadro 17 - The Mediterranean Ammophiletea Database

\begin{tabular}{l|l}
\hline \multicolumn{1}{c|}{ Critérios } & \multicolumn{1}{c}{ Descrição } \\
\hline 1 - Nome da fonte & The Mediterranean Ammophiletea Database \\
\hline 2 - Identificação do responsável & Biblioteca Mann da Universidade de Cornell, Ithaca, NY. \\
\hline 3 - Conteúdo & $\begin{array}{l}\text { O principal objetivo foi compilar, em um repositório único, } \\
\text { dados de parcelas de vegetação de comunidades herbáceas } \\
\text { psamófilas (classes fitossociológicas de Ammophiletea e } \\
\text { Helichryso-Crucianelleteamaritimae) do sul da Europa e } \\
\text { norte da África. }\end{array}$ \\
\hline 4 - Aquisição & $\begin{array}{l}\text { Conrado Maceno - Gerente de banco de dados } \\
\text { marcenocorrado@libero.it }\end{array}$ \\
\hline 5 - Início da produção & Suas atividades tiveram início em 2014. \\
\hline 6 - Forma de disponibilização & Disponível em: https://www.givd.info/ID/EU-00-016 \\
\hline 7 - Número de registros & 200 fontes indexadas. \\
\hline 8 - Cobertura tópica & $\begin{array}{l}\text { Assuntos relacionados a pesquisas na área de vegetação de } \\
\text { comunidades herbáceas psamófilas. }\end{array}$ \\
\hline 9 - Cobertura geográfica & Engloba o sul da Europa e norte da África. \\
\hline 10 - Tempo de cobertura & Não informado. \\
\hline 11 - Frequência de atualização & Última atualização foi em 2018. \\
\hline 12 - Serviços relacionados & $\begin{array}{l}\text { É possível fazer o download em pdf das referências } \\
\text { disponibilizadas. }\end{array}$ \\
\hline 13 - Outras observações & $\begin{array}{l}\text { A ideia para a criação do banco de dados partiu através do } \\
\text { nono evento ocorrido na Alemanha (Hamburgo), em que foi } \\
\text { decidido estabelecer uma base de dados global de vegetação. }\end{array}$ \\
\hline 14 - Data da coleta de dados & 18 de março de 2019. \\
\hline
\end{tabular}

Fonte: Dados da pesquisa, 2018.

O The Mediterranean Ammophiletea Database é um repositório que contém aproximadamente 10.000 espécies relevantes da bacia do Mediterrâneo, do lado do Atlântico Sul da Europa (Marrocos, Portugal e Espanha) e do Mar Negro. Esse banco de dados está registrado no Global Index of Vegetation Database (GIVD) e está disponível mediante solicitação no European Vegetation Archive (EVA). 
Quadro 18 - African Plant Database

\begin{tabular}{l|l}
\hline \multicolumn{1}{c|}{ Critérios } & \multicolumn{1}{c}{ Descrição } \\
\hline 1 - Nome da fonte & African Plant Database \\
\hline 2 - Identificação do responsável & Não especificado. \\
\hline 3 - Conteúdo & $\begin{array}{l}\text { Atualmente compreende 202.559 nomes de plantas africanas } \\
\text { com seus estatutos e nomenclaturas. }\end{array}$ \\
\hline 4- Aquisição & cyrille.chatelain@ ville-ge.ch \\
\hline 5 - Início da produção & Suas atividades tiveram início em 2012. \\
\hline 6 - Forma de disponibilização & $\begin{array}{l}\text { Disponível em: } \\
\text { ge.ch/musinfo/bd/cjb/africa/recherche.php }\end{array}$ \\
\hline 7 - Número de registros & Compreende 203.277 nomes de plantas indexadas. \\
\hline 8 - Cobertura tópica & Assuntos relacionados a pesquisas agrícolas. \\
\hline 9 - Cobertura geográfica & Pretende cobrir todo o continente africano. \\
\hline 10 - Tempo de cobertura & Não informado. \\
\hline 11 - Frequência de atualização & Última atualização foi em 2018. \\
\hline 12 - Serviços relacionados & Links de fontes relacionadas são disponibilizados no site. \\
\hline 13 - Outras observações & $\begin{array}{l}\text { A fonte não apresenta informações detalhadas de } \\
\text { identificação. }\end{array}$ \\
\hline 14 - Data da coleta de dados & 18 de março de 2019.
\end{tabular}

Fonte: Dados da pesquisa, 2018.

A African Plant Database é um banco de dados que reúne os nomes de plantas africanas apresentando informações sobre: tipos nomenclaturais, sinônimos heterotípicos, informações sobre o gênero, família botânica e referências. A captura, a edição e a transmissão de dados são resultados de uma colaboração de South African National Biodiversity Institute, Conservatoire et Jardin botaniques de la Ville de Genève, Tela Botanica e Missouri Botanical Garden. Os dados são atualizados regularmente, seguindo a literatura.

Quadro 19 - The Northern African Natural Products Database

\begin{tabular}{l|ll}
\hline \multicolumn{1}{c|}{ Critérios } & \multicolumn{3}{|c}{ Descrição } \\
\hline 1 - Nome da fonte & $\begin{array}{l}\text { The Northern African Natural Products Database } \\
\text { (NANPDB) }\end{array}$ \\
\hline 2 - Identificação do responsável & $\begin{array}{l}\text { Universidade de Freiburg - Instituto de Ciências } \\
\text { Farmacêuticas e Bioinformática Farmacêutica }\end{array}$ \\
\hline 3 - Conteúdo & $\begin{array}{l}\text { Consiste em dados detalhando compostos vegetais com } \\
\text { contribuições de endófitos, animais (por exemplo, corais), } \\
\text { fungos e algumas fontes de bactérias. Inclui também dados } \\
\text { de organismos de origem, referências, atividades biológicas e } \\
\text { modos de ação (antimaláricos, anticancerígenos, citotóxicos). }\end{array}$ \\
\hline 4- Aquisição & $\begin{array}{l}\text { Prof. Dr. Stefan Günther } \\
\text { Universidade de Freiburg Instituto de Ciências } \\
\text { Farmacêuticas e BioinformáticaFarmacêutica Hermann- }\end{array}$ \\
\hline
\end{tabular}




\begin{tabular}{l|l}
\hline & $\begin{array}{l}\text { Herder-Strasse 9. Tel: + 49-761-203-4871 - Fax: + 49-761- } \\
\text { 203-97769 } \\
\text { nsnpdb@ african-compouds.org }\end{array}$ \\
\hline 5 - Início da produção & Suas atividades tiveram início em 2012. \\
\hline 6 - Forma de disponibilização & Disponível em: http://african-compounds.org/nanpdb/ \\
\hline 7 - Número de registros & Não especificado. \\
\hline 8 - Cobertura tópica & $\begin{array}{l}\text { O banco de dados tenta fornecer um ponto de referência para } \\
\text { as centenas de produtos naturais bioativos nativos da região } \\
\text { Norte da África, que poderiam ser um importante } \\
\text { reservatório para a descoberta de drogas. }\end{array}$ \\
\hline 9 - Cobertura geográfica & Norte da África. \\
\hline 10 - Tempo de cobertura & Não especificado. \\
\hline 11 - Frequência de atualização & Não especificado. \\
\hline 12 - Serviços relacionados & $\begin{array}{l}\text { Dados estatísticos disponibilizados relacionados a medicina } \\
\text { popular do norte africano. }\end{array}$ \\
\hline 13 - Outras observações & Link do grupo de pesquisas em química www.cbic-africa.org. \\
\hline 14 - Data da coleta de dados & 18 de março de 2019. \\
\hline
\end{tabular}

Fonte: Dados da pesquisa, 2018.

O Northern African Natural Products Database (NANPDB) reúne informações sobre 4.500 produtos naturais bioativos do Norte da África. Os dados cobrem compostos isolados de plantas, com contribuições de algum endófito, por exemplo, corais, fungos e fontes bacterianas. Os compostos foram identificados a partir de 617 espécies-fonte, pertencentes a 146 famílias. O NANPDB pode ser útil para os esforços de descoberta de medicamentos, análise da bioatividade de compostos selecionados ou a descoberta de rotas de síntese para metabólitos secundários.

\section{Categoria 4 - Fontes de Informação em Saúde}

Foi encontrada e selecionada apenas 01 fonte de informação relacionada à temática da saúde. Essa temática é composta por literatura sobre saúde, medicina, ambientes hospitalares e áreas correlatas.

Quadro 20 - African Index Medicus Database

\begin{tabular}{l|l}
\hline \multicolumn{1}{c|}{ Critérios } & \multicolumn{1}{c}{ Descrição } \\
\hline 1 - Nome da fonte & African Index Medicus Database - AIM \\
\hline 2 - Identificação do responsável & $\begin{array}{l}\text { African Index Medicus Database- Global Index Medicus - } \\
\text { Congo. }\end{array}$ \\
\hline $3-$ Conteúdo & $\begin{array}{l}\text { É especializada em acesso à informação sobre saúde } \\
\text { publicada ou relacionada com África. }\end{array}$ \\
\hline $4-$ Aquisição & Pascal Mouhouelo (Coordenação/chefe da Biblioteca) \\
\hline
\end{tabular}




\begin{tabular}{l|l}
\hline & $\begin{array}{l}\text { MikhaelEyinat (Gestão da Base de Dados) } \\
\text { Marie Claudine (Responsável pela indexação e coleção } \\
\text { histórica da biblioteca) } \\
\text { Carine Sounga (Assessoria Estratégica e Técnica) } \\
\text { E-mail: afrgoafrolibrary@ who.int } \\
\text { Telefone: + 47-241-39 673 }\end{array}$ \\
\hline 5 - Início da produção & Em formato eletrônico desde 2002. \\
\hline 6 - Forma de disponibilização & $\begin{array}{l}\text { Disponível } \\
\text { http://indexmedicus.afro.who.int/aim/opac_css/?database=bi } \\
\text { blohttp://search.bvsalud.org/ghl/?lang=en\&submit=Search\& }\end{array}$ \\
\hline where=REGIONAL \\
\hline 8 - Cobertura tópica & $\begin{array}{l}\text { Indexa mais de 250 jornais africanos de saúde; Mais de 1000 } \\
\text { pesquisas de doutorado e mais de 16000 publicações } \\
\text { voltadas a área da saúde. }\end{array}$ \\
\hline 9 - Cobertura geográfica & $\begin{array}{l}\text { Assuntos relacionados à nutrição, pediatria, gestão ambiental } \\
\text { de países do continente africano. Apresenta também } \\
\text { informações sobre medicina internacional. }\end{array}$ \\
\hline 10 - Tempo de cobertura & O continente africano. \\
\hline 11 - Frequência de atualização & Não informado. \\
\hline 12 - Serviços relacionados & A última atualização foi em janeiro de 2019. \\
\hline 13 - Outras observações & Acesso direto ao AfroLibe e ao Observatório de saúde. \\
\hline 14 - Data da coleta de dados & $\begin{array}{l}\text { Possui vínculo com a Organização Mundial de Saúde, em } \\
\text { colaboração com a Associação para Informação e Bibliotecas } \\
\text { de Saúde em África. }\end{array}$ \\
\hline 05 de março de 2019. \\
\hline
\end{tabular}

Fonte: Dados da pesquisa, 2018.

O African Index Medicus Database (AIM) foi produzido para dar acesso à literatura africana e as fontes de informação em saúde publicadas sobre a África. O AIM promove as publicações africanas incentivando os escritores a publicar em seus periódicos nacionais ou regionais, enquanto cientistas e pesquisadores de países em desenvolvimento estão competindo pelo espaço de publicação nos poucos periódicos "prestigiados" existentes pelo mundo. Há uma riqueza de informações inexploradas em livros, relatórios e estudos de agências internacionais de desenvolvimento, organizações não governamentais e instituições locais.

\section{CONSIDERAÇÕES FINAIS}

A presente reflexão não poderia suspender-se, antes de tocar, ainda que de forma pontual, no papel a ser assumido pelo bibliotecário e demais profissionais da informação, num mundo em que, conforme explicitado por Cunha (2010), “conhecimento é poder”. Exige-se, 
sobretudo dos bibliotecários, uma postura disruptiva no contexto vigente de uma Sociedade da Informação. O mercado que negocia, se nutre e vive da comercialização de fontes de informação (aí inclusa as de caráter especializado) não ignora que o que elas de fato transacionam é "informação" e, como também acentuado por Varela (2007, p. 77), “conhecimento é poder". Logo, é necessário acumular familiaridade com esses artefatos para desviar-se, o quanto possível, das ciladas inerentes aos interesses conflitantes que atuam nessa arena.

As dificuldades encontradas no desenvolvimento do presente trabalho permitiram perceber que o tema ainda é pouco explorado na literatura em Ciência da Informação, o que explicaria, em parte, a relativa escassez de documentos. Outro fator observado é que as fontes, na maioria das vezes, são insuficientemente descritas, isto é, nem sempre apresentam elementos essenciais de identificação, tais como: objetivos, finalidades e número de registros bibliográficos cadastrados. Foi notado, também, que nem todas as fontes são atualizadas com periodicidade regular, constando, em alguns casos, em seus sites atualizações de três a quatro anos atrás.

Ademais, chamou a atenção, no percurso de observação das características das 19 fontes de informação identificadas e aqui descritas, que apenas quatro são de responsabilidade de países africanos (Congo e África do Sul). As outras estão a cargo de países europeus e norte americano. Esse parece ser um importante traço a demandar verticalizações reflexivas no eixo do desenvolvimento de coleções, ou, ainda, dos estudos dedicados ao processo de comunicação científica.

Por fim, e tão importante quanto, em tempos cibernéticos, em que parece haver tanta oferta de tudo, o saber especialista do bibliotecário é conclamado no sentido de capacitar para o uso das fontes de informação especializada, bem como, no encaminhamento, dentro de sua esfera de atuação, de atitudes que reforcem ou disparem, conforme Aida Varela (2007, p. 143), a "cidadania emancipatória" dos consulentes, dos usuários dessas fontes. E, de igual modo, a reconfiguração dos produtores e disseminadores de conhecimento científico, em cujas agendas de pesquisa, quaisquer que sejam as facetas das africanidades, quando tomadas enquanto objetos de reflexão, o sejam enquanto possibilidade de fortalecimento e força motriz de uma travessia descolonizatória na relação com o continente africano. 


\section{REFERÊNCIAS}

CAMPELLO, B.S; CALDEIRA, P. da T. Introdução às fontes de informação. 2. ed. Belo Horizonte: Autêntica, 2008. 184 p.

CENDÓN, B.V. Bases de dados de informação para negócios no Brasil. Ciência da Informação, Brasília, v. 32, n. 2, p 17-36, maio/ago. 2003.

CENDÓN, B.V. Sistemas e redes de informação. In: OLIVEIRA, M. (Coord.). Ciência da informação e Biblioteconomia: novos conteúdos e espaços de atuação. Belo Horizonte: Ed. UFMG, 2005. Cap. 4. p. 61-96.

FEDERAÇÃO Brasileira de Associações de Bibliotecários. Comissão Brasileira de Bibliotecas Universitárias. Lista de discussão. Disponível em: www.febab.org.br/cbbu/listade-discussão. Acesso em: 11 mar. 2019.

CUNHA, M.B. da. Manual de fontes de informação. Brasília: Briquet de Lemos, 2010. 182 p.

ECO, U. Interpretação e superinterpretação. São Paulo: Martins Fontes, 1993.

GUIMARÃES, A. de M. Internet. In: CAMPELLO, B.S; CALDEIRA, P. da T. Introdução às fontes de informação. 2. ed. Belo Horizonte: Autêntica, 2008. p. 159-178.

JARDIM, J.M.; FONSECA, M.O. Arquivos. In: CAMPELLO, B.S; CALDEIRA, P. da T. Introdução às fontes de informação. 2. ed. Belo Horizonte: Autêntica, 2008. p.121-140.

KI-ZERBO, J. Introdução geral. In: KI-ZERBO, J. (Ed.). História geral da África: metodologia e pré-história da África. 3. ed. Brasília: UNESCO, 2011. v. 1. p. xxxi-lvii.

M'BOW, M.A.M. Prefácio. In: KI-ZERBO, J. (Ed.). História geral da África: metodologia e pré-história da África. 3. ed. Brasília: UNESCO, 2011. v. 1. p. xxi-xxvi.

ORGANIZAÇÃO das Nações Unidas para a Educação, Ciência e Cultura. Reunião do Comitê Científico Internacional para o [lançamento] do volume IX da Coleção História Geral da África. 2019. Disponível em: http://domhelder.edu.br/eventos/language/pt/calendario/hga/. Acesso em: 20 mar. 2019.

SOUZA, P.C.A. de. Educar-se ao mundo: percepções acerca das africanidades. Revista Espaço Acadêmico, n. 106, p. 149-159, mar. 2010.

VARELA, A. Informação e construção da cidadania. Brasília: Thesaurus, 2007. 167 p. 